\title{
Organosolv pretreatment of sorghum bagasse using a low concentration of hydrophobic solvents such as 1-butanol or 1-pentanol
}

\author{
Hiroshi Teramura' ${ }^{1}$ Kengo Sasaki ${ }^{2}$, Tomoko Oshima ${ }^{1}$, Fumio Matsuda 3,4, Mami Okamoto ${ }^{4}$, Tomokazu Shirai ${ }^{4}$, \\ Hideo Kawaguchi' , Chiaki Ogino' , Ko Hirano ${ }^{5}$, Takashi Sazuka ${ }^{5}$, Hidemi Kitano ${ }^{5}$, Jun Kikuchi ${ }^{4,6,7}$ \\ and Akihiko Kondo ${ }^{1,4^{*}}$
}

\begin{abstract}
Background: The primary components of lignocellulosic biomass such as sorghum bagasse are cellulose, hemicelIulose, and lignin. Each component can be utilized as a sustainable resource for producing biofuels and bio-based products. However, due to their complicated structures, fractionation of lignocellulosic biomass components is required. Organosolv pretreatment is an attractive method for this purpose. However, as organosolv pretreatment uses high concentrations of organic solvents ( $>50 \%$ ), decreasing the concentration necessary for fractionation would help reduce processing costs. In this study, we sought to identify organic solvents capable of efficiently fractionating sorghum bagasse components at low concentrations.

Results: Five alcohols (ethanol, 1-propanol, 2-propanol, 1-butanol, and 1-pentanol) were used for organosolv pretreatment of sorghum bagasse at a concentration of $12.5 \%$. Sulfuric acid (1\%) was used as a catalyst. With 1-butanol and 1-pentanol, three fractions (black liquor, liquid fraction containing xylose, and cellulose-enriched solid fraction) were obtained after pretreatment. Two-dimensional nuclear magnetic resonance analysis revealed that the lignin aromatic components of raw sorghum bagasse were concentrated in the black liquor fraction, although the major lignin side-chain ( $\beta$-O-4 linkage) was lost. Pretreatment with 1-butanol or 1-pentanol effectively removed $p$-coumarate, some guaiacyl, and syringyl. Compared with using no solvent, pretreatment with 1-butanol or 1-pentanol resulted in two-fold greater ethanol production from the solid fraction by Saccharomyces cerevisiae.

Conclusions: Our results revealed that a low concentration (12.5\%) of a highly hydrophobic solvent such as 1-butanol or 1-pentanol can be used to separate the black liquor from the solid and liquid fractions. The efficient delignification and visible separation of the lignin-rich fraction possible with this method simplify the fractionation of sorghum bagasse.
\end{abstract}

Keywords: Sorghum bagasse, Organosolv pretreatment, Fractionation, 1-butanol, 1-pentanol, Lignin

\section{Background}

The depletion of fossil fuels and environmental pollution associated with fossil fuel use have increased interest in

\footnotetext{
${ }^{*}$ Correspondence: akondo@kobe-u.ac.jp

${ }^{1}$ Department of Chemical Science and Engineering, Graduate School of Engineering, Kobe University, 1-1 Rokkodaicho, Nada-ku, Hyogo, Kobe 657-8501, Japan

Full list of author information is available at the end of the article
}

the utilization of biomass as a feedstock for the production of biofuels and bio-based chemicals [1, 2]. Starchrich biomass is one of the main feedstocks used for these purposes; however, this results in direct competition with global food supplies. Lignocellulosic biomass is a promising alternative feedstock because it is abundant, inexpensive, and renewable. Sorghum (Sorghum bicolor L. Moench), which is a highly productive $\mathrm{C} 4$ photosynthetic 
plant, can be used to produce lignocellulosic fractions. Sorghum is also attractive because it uses water efficiently and is drought tolerant [3]. The lignocellulosic fraction produced from sorghum is typically referred to as sorghum bagasse.

The primary components of sorghum bagasse are cellulose, hemicellulose, and lignin [4], each of which can be valorized. For example, cellulose and hemicellulose are used as carbohydrate sources for fermentation, whereas cellulose pulp is used for paper, and lignin is a renewable source of aromatics [5-7]. The fractionation of sorghum bagasse into its primary components can be carried out in a biorefinery $[5,8]$. However, because cellulose is highly crystalline in nature, exhibits complex chemical cross-linking between components, and is recalcitrant to hydrolysis due to the sheathing by hemicellulose and lignin, the fractionation of sorghum bagasse requires appropriate pretreatment $[9,10]$. Organosolv pretreatment is a practical methodology for fractionating sorghum bagasse because it facilitates the isolation of high-quality lignin and high-purity cellulose [2, 11, 12]. Organosolv pretreatment involves the use of highconcentration (30-70\%) organic or aqueous organic solvents at temperatures of $100-200{ }^{\circ} \mathrm{C}$, with or without the addition of catalysts [13]. Thus, organosolv pretreatment is expensive and necessitates the recovery of the organic solvents used. Decreasing the concentration of organic solvent necessary for effective pretreatment would thus reduce the cost of fractionation.

As indicated above, organosolv pretreatment has the advantage of enabling the isolation of lignin [2]. The composition of plant cell walls can be characterized by two-dimensional ${ }^{1} \mathrm{H}_{-}{ }^{13} \mathrm{C}$ heteronuclear single-quantum coherence nuclear magnetic resonance $\left(2 \mathrm{D}{ }^{1} \mathrm{H}-{ }^{13} \mathrm{C}\right.$ HSQC NMR) spectroscopy $[14,15]$. Thus, 2D-NMR spectroscopy can be used to elucidate the fate of lignin during organosolv pretreatment of sorghum bagasse.

The aim of the present study was to investigate the fractionation effectiveness of five different organic solvents (ethanol, 1-propanol, 2-propanol, 1-butanol, and 1 -pentanol) at a relatively low concentration (12.5\%) in organosolv pretreatment of sorghum bagasse. Sulfuric acid was used as the catalyst. The detailed structures of the lignin products obtained in the black liquor and solid fraction of samples pretreated with 1-butanol or 1-pentanol were characterized using $2 \mathrm{D}^{1} \mathrm{H}_{-}{ }^{13} \mathrm{C}$ HSQC NMR spectroscopy.

\section{Results and discussion}

The influence of solvent type on organosolv fractionation of sorghum bagasse

Sorghum bagasse was fractionated into three primary components important in biorefinery processes: cellulose, hemicellulose, and lignin. In this study, fractionation was evaluated by comparing pretreatment using five different organic solvents (ethanol, 1-propanol, 2-propanol, 1-butanol, and 1-pentanol) at a low concentration $(12.5 \%)$. Pretreatment with no addition of solvent was used as a control.

After treatment at $180{ }^{\circ} \mathrm{C}$ for $45 \mathrm{~min}$, samples were centrifuged (Fig. 1). Interestingly, three fractions (solid, liquid, and black liquor) were obtained with 1-butanol or 1-pentanol as the solvent, but only two fractions (solid and liquid) were obtained using ethanol, 1-propanol, or 2-propanol as the solvent and when no solvent was used (control). These results suggest that differences in the physiochemical properties of the solvents affect fractionation. The greater hydrophobicity of 1-butanol and 1-pentanol (partition coefficients: $\log P_{\text {ow }}=0.88$ and 1.51, respectively) compared with ethanol, 1-propanol, and 2 -propanol $\left(\log P_{\text {ow }}=-0.31,0.25\right.$, and 0.05 , respectively) resulted in clearer fractionation when using the former solvents. The control condition was equal to dilute acid pretreatment [16]. Thus, hydrophobic 1-butanol and 1-pentanol separated the black liquor fraction from the acid solution even at the low concentration of $12.5 \%$.

\section{Cellulose-enriched solid fraction}

To clarify the effect of solvent type on raw sorghum bagasse, the solid fraction obtained after pretreatment was characterized. Compared with the control, the dry weight of the solid fraction decreased when 1-butanol or 1-pentanol was used as the solvent, but ethanol, 1-propanol, and 2-propanol had no effect on solid fraction dry weight (Fig. 2a). Cellulose is reportedly enriched in the solid fraction of samples pretreated using acid [9], and an increase in the cellulose content in all solid fractions was observed compared with the raw biomass (Fig. 2b). In particular, the cellulose content was higher in the solid fraction when 1-butanol or 1-pentanol was used as the solvent (59.1 and $62.2 \%$, respectively) compared with ethanol, 1-propanol, 2-propanol, or no solvent (control) (51.6-55.6\%). Cellulose recovery in the solid fraction ranged from 84.4 to $91.1 \%$ when ethanol, 1-propanol, 2-propanol, or 1-butanol was used as the solvent and when no solvent was used (control) (Additional file 1). Cellulose recovery in the solid fraction was $71.9 \%$ when 1-pentanol was used as the solvent. Similar to the trend with dry weight (Fig. 2a), the acid-insoluble lignin content was lower in the solid fraction when 1-butanol or 1-pentanol was used as the solvent compared with other solvents (Fig. 2b). Accordingly, the greatest increase in glucose yield compared with the control was observed with 1-butanol or 1-pentanol as the solvent, but increased glucose yield was also observed with ethanol, 1-propanol, and 2-propanol (Fig. 2c). 


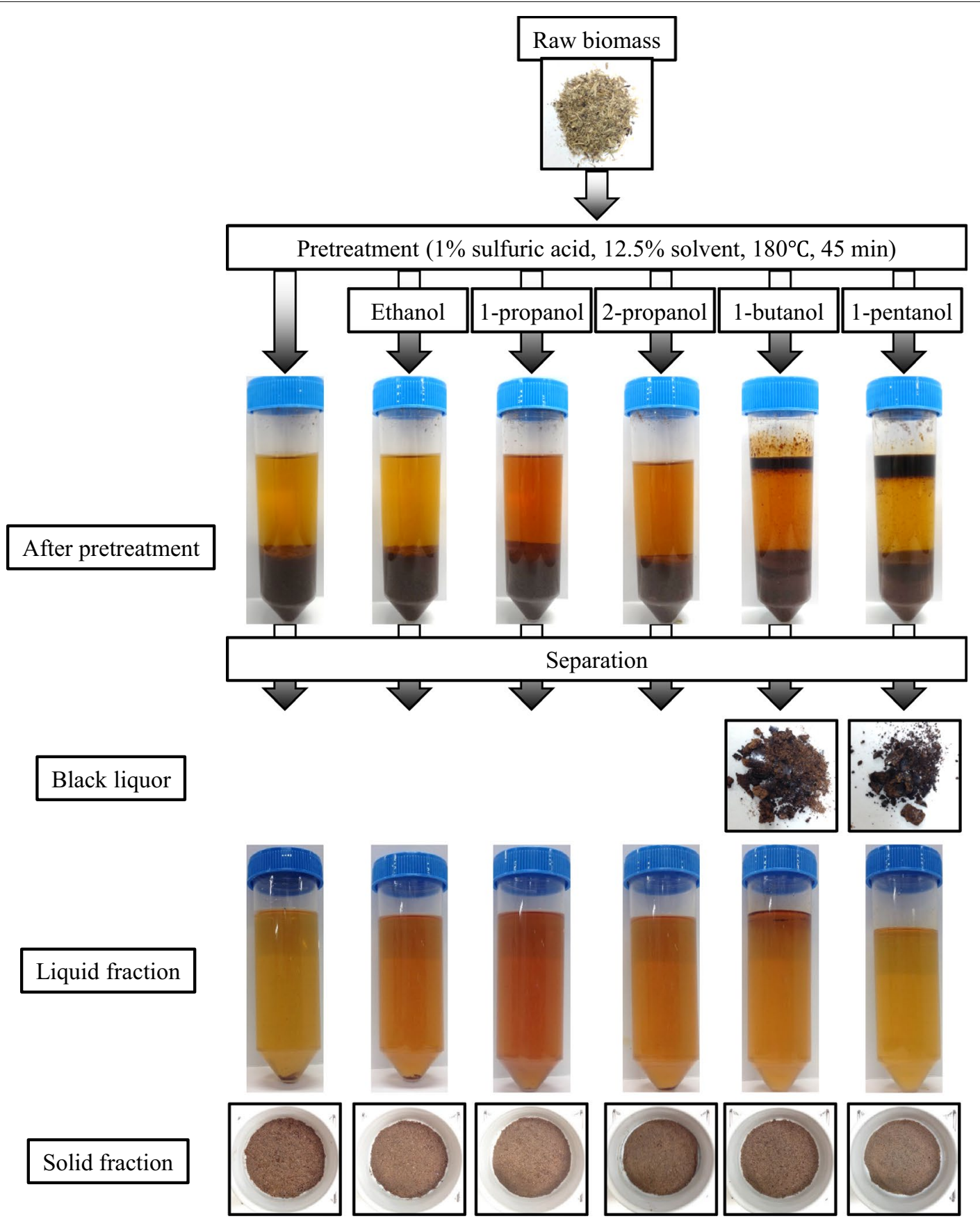

Fig. 1 Organosolv pretreatment of sorghum bagasse using 12.5\% solvent concentration. Ethanol, 1-propanol, 2-propanol, 1-butanol, and 1-pentanol were used as the solvent. No addition of solvent was the control. Using ethanol, 1-propanol, and 2-propanol as the solvent and no solvent (control), a solid fraction and a liquid fraction were obtained. Using 1-butanol and 1-pentanol as the solvent, a black liquor fraction was obtained in addition to solid and liquid fractions

Lignin removal, as calculated using the equation [(lignin in bagasse) - (lignin in solid fraction)]/(lignin in bagasse), was higher when 1-butanol or 1-pentanol was used as the solvent (64.7-74.3\%), compared with the use of no solvent, ethanol, 1-propanol, or 2-propanol (44.149.7 \%) (Fig. 2a, b). Lignin, which is degraded by sulfuric acid, is reportedly liberated from the cell wall and forms droplets that attach to cellulose molecules [17]. Hydrophobic alcohols would dissolve these lignin droplets and prevent their attachment to cellulose. The removal of lignin from cellulose reportedly increases the accessibility to hydrolytic enzymes and reduces the degree of 
a

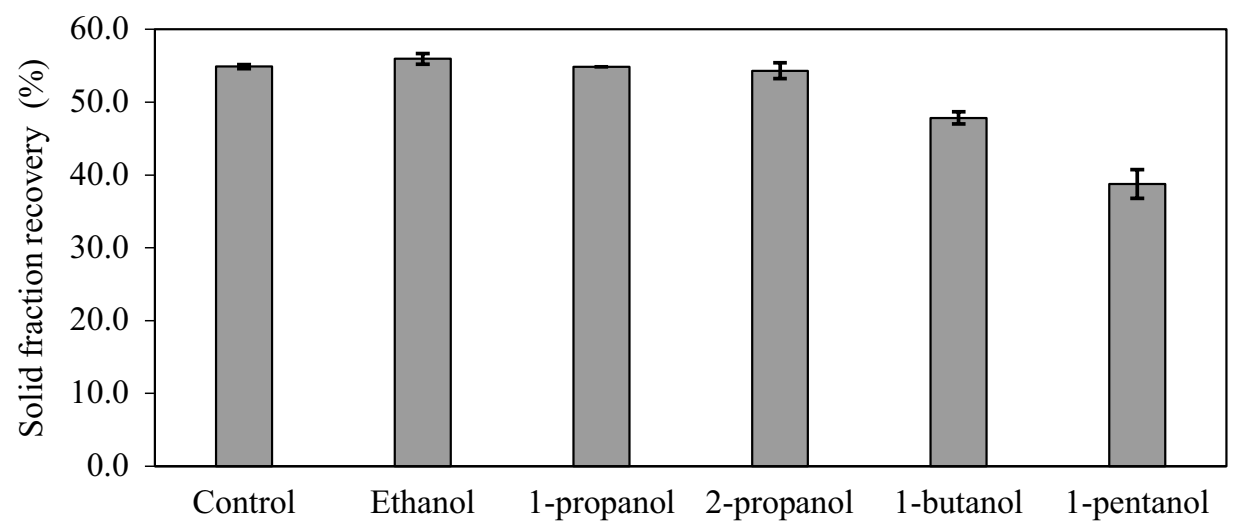

b

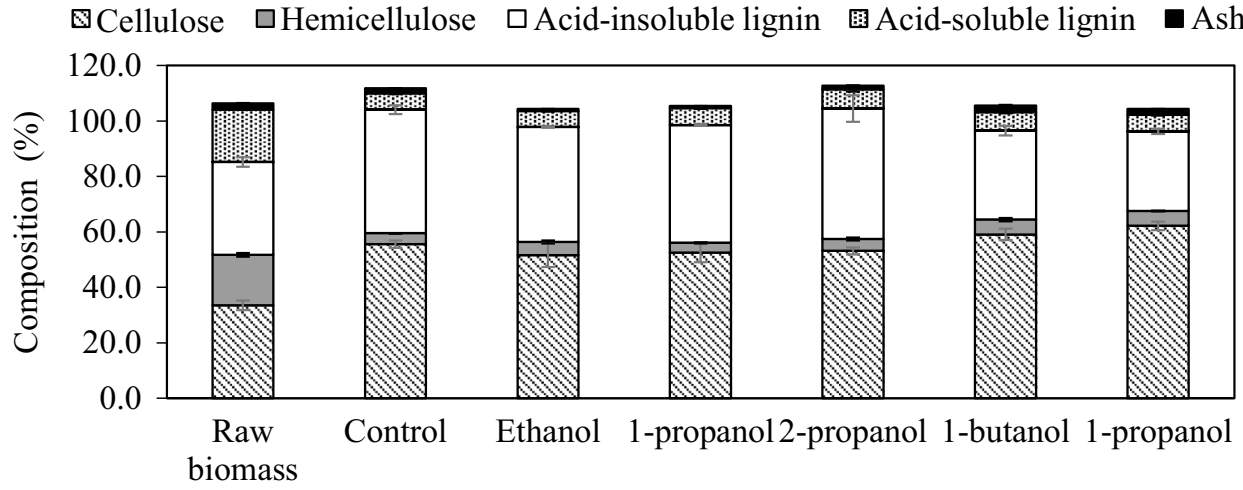

c

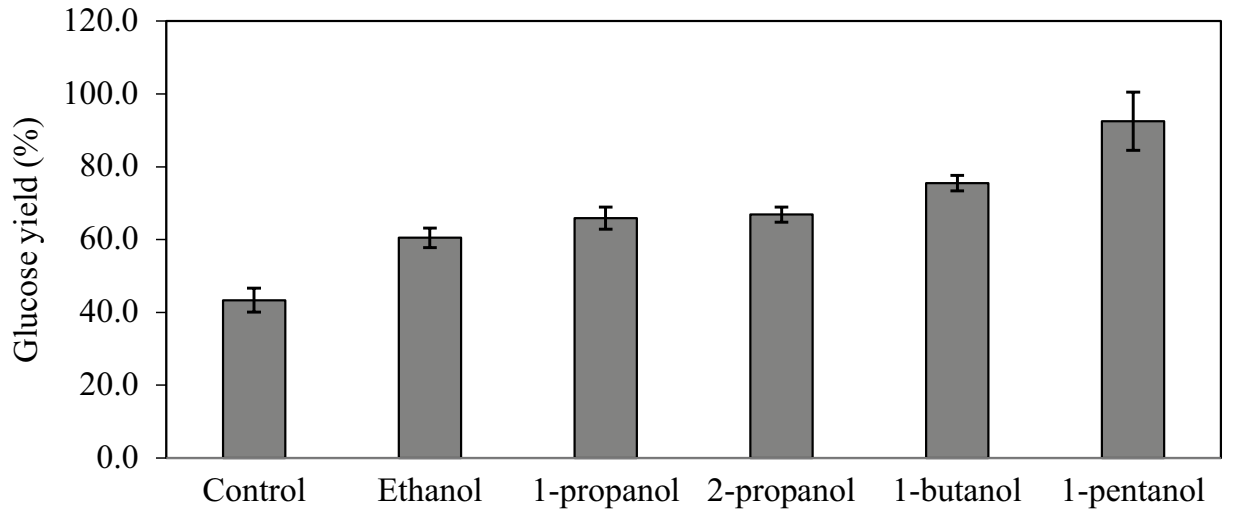

Fig. 2 Properties of the solid fraction obtained after organosolv pretreatment. a Weight of the solid fraction obtained after pretreatment. b Carbohydrate and lignin composition of the solid fraction. c Glucose yield from the solid fraction. Organosolv pretreatment of sorghum bagasse was carried out using ethanol, 1-propanol, 2-propanol, 1-butanol, and 1-pentanol as the solvent and no solvent (control)

irreversible adsorption of the enzyme to lignin [18]. Thus, organosolv pretreatment using 1-butanol or 1-pentanol efficiently removes acid-insoluble lignin, resulting in enhanced enzymatic hydrolysis of cellulose.

\section{Liquid fraction containing hemicellulose-derived sugars} It was expected that hemicellulose-derived sugars, mainly xylose, would be contained in the liquid fraction
[2]. The amount of xylose contained in the liquid fraction of samples pretreated with ethanol, 1-propanol, 2-propanol, 1-butanol, 1-pentanol, or with no solvent (control) was similar (Fig. 3a). The xylose recovery in the liquid fraction was higher (90.6-97.4 \%) when using ethanol, 1-propanol, 1-pentanol, or no solvent, compared with 2-propanol and 1-butanol (85.5 and 79.2\%, respectively), as calculated using the following equation: 


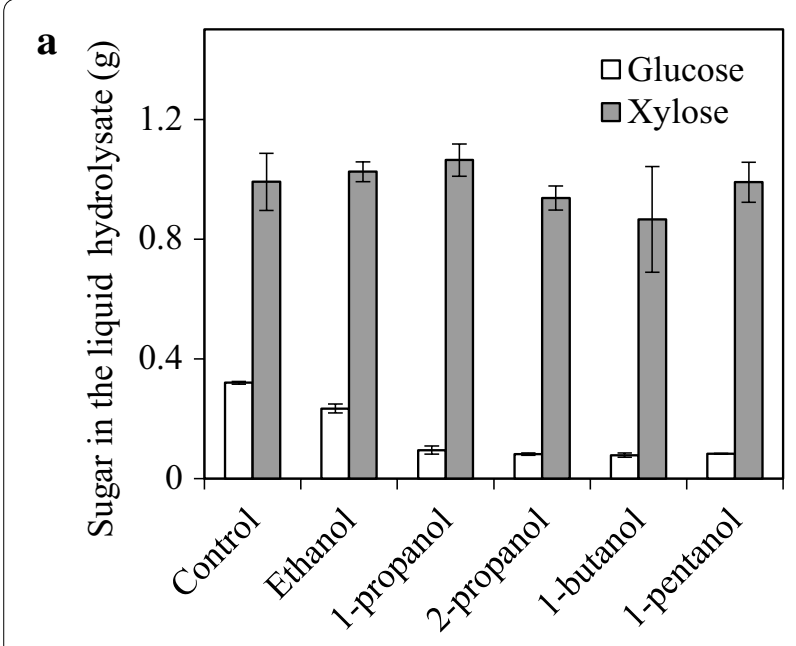

b

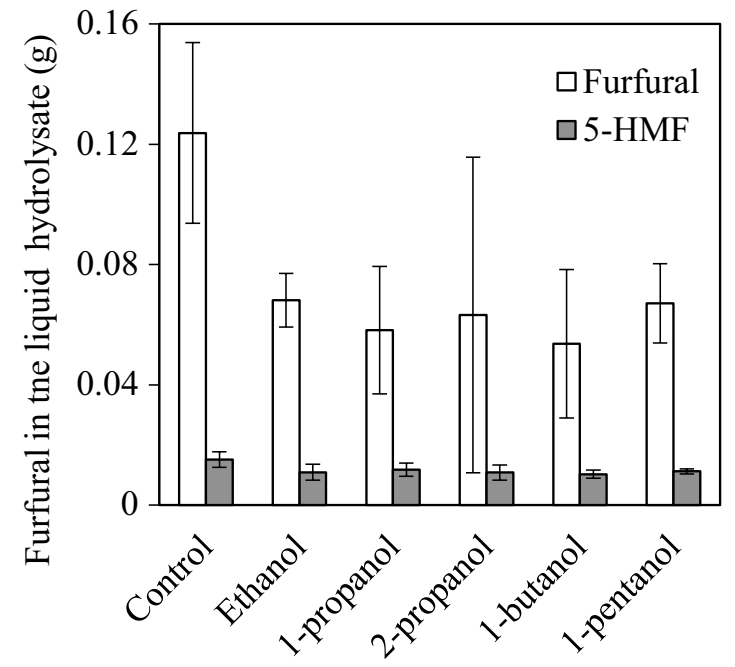

c

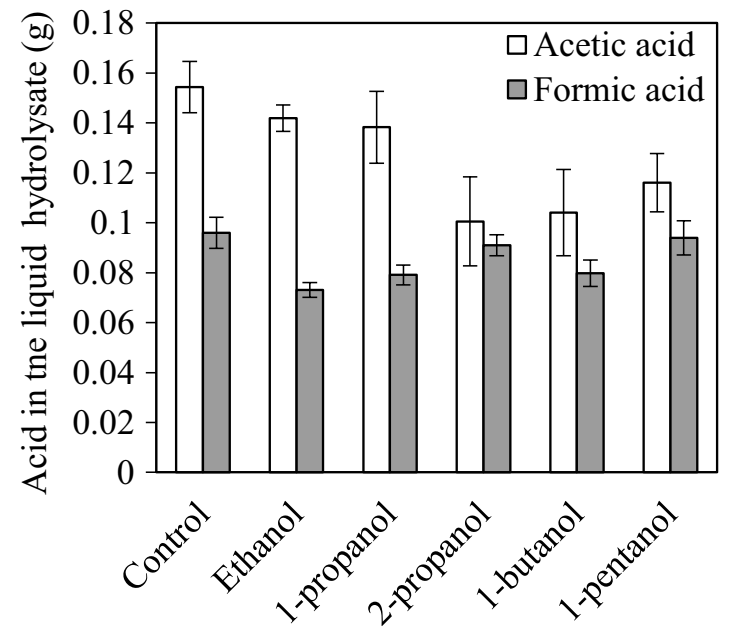

Fig. 3 Composition of the liquid fraction. a Glucose and xylose. $\mathbf{b}$ Furfural and 5-HMF. c Acetic acid and formic acid. The amount (g) of each component obtained from $6 \mathrm{~g}$ of raw biomass is shown (xylose amount in liquid fraction)/[(total xylose)—(xylose amount in solid fraction)]. The reason for the decreased xylose recovery when using 2-propanol or 1-butanol as the solvent is unclear.

Compared with the control, the amount of glucose in the liquid fraction was lower in the solvent-pretreated samples (Fig. 3a). Furfural and 5-hydroxymethylfurfural (5-HMF) were contained in the liquid fraction (Fig. 3b). The harsh conditions of pretreatment resulted in the production of similar amounts of acetic and formic acids in the liquid fraction (Fig. 3c). In addition, solvents were blended in the liquid fraction (data not shown). The presence of acetic and formic acids, furfural, 5-HMF, and the pretreatment solvent would inhibit subsequent fermentation. These fermentation inhibitors could be removed, and the xylose and glucose in the liquid fraction could be concentrated, by subsequent application of membrane separation nanofiltration $[19,20]$.

\section{Lignin contained in the black liquor fraction}

A black liquor fraction was obtained when $12.5 \%$ 1-butanol or 1-pentanol was used as the solvent (Fig. 1). Lignin was precipitated from the black liquor fraction by dilution with water [2]. Lignin recovery, as calculated using the equation (lignin in black liquor)/[(lignin in raw biomass) -(lignin in solid fraction)], was 12.5 and $25.6 \%$ using 1-butanol or 1-pentanol as the solvent, respectively, corresponding to 8.1 and $19.1 \%$ lignin content in the raw sorghum bagasse, respectively (Fig. 4). The lignin recovery in the present study was similar to that of a previous study, which reported 5.1-17.2 \% lignin recovery from wheat straw pretreated with $50-60 \%$ ethanol at $190-210^{\circ} \mathrm{C}$ [5]. However, our lignin recovery was lower than that from rye straw pretreated at $190^{\circ} \mathrm{C}$ for $3 \mathrm{~h}$ at a $1.3 \%$ acid concentration (35\%) [21]. Therefore, process optimization of lignin recovery with respect to solvent concentration, temperature, time, and acid concentration will be necessary in the future. It is also possible that low lignin recovery was due to the loss of water-soluble products from lignin degradation [21].

Next, the composition and structure of the lignins in the black liquor fraction were analyzed using $2 \mathrm{D}^{1} \mathrm{H}_{-}{ }^{13} \mathrm{C}$ HSQC NMR [15]. The syringyl, guaiacyl, and $p$-hydroxyphenyl lignin units are important aromatic elements of the plant cell wall [22]. Strong signals related to these lignin components (regions of interest [ROIs] 7-13) were detected in the black liquor, compared with raw sorghum bagasse (Fig. 5 and Additional file 2). Other strong signals related to aromatic components, such as $p$-coumarate (ROIs 1-6) and ferulate (ROIs 15 and 16), were detected in the black liquor. The only aromatic region signal that 


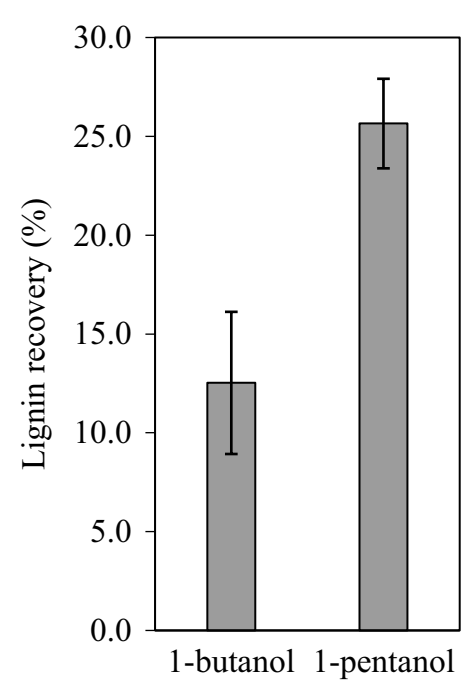

Fig. 4 Yield of lignin in black liquor. Lignin recovery was calculated as follows: (lignin in black liquor)/[(lignin in raw biomass)_(lignin in solid fraction)]

was weaker in the black liquor was that related to cinnamyl alcohol (ROI 14). Accordingly, signals related to methoxyl (ROIs 17 and 18) groups were stronger, as methoxyl groups are found in the side chains of syringyl, guaiacyl, and ferulate [23].

In contrast, the signal related to a major interunit structure, $\beta-\mathrm{O}-4$ (ROI 24), was weaker in the black liquor than in raw sorghum bagasse. This was probably due to partial cleavage of the thermally labile $\beta-\mathrm{O}-4$ unit in raw sorghum bagasse under heat treatment [24, 25]. Another signal (ROI 25) related to the $\beta-\mathrm{O}-4$ unit was stronger in the black liquor, but the reason for this difference is unclear. Signals related to other minor interunit structures in raw sorghum bagasse were either stronger or weaker in the black liquor. These results suggest that most of the lignin aromatic components were concentrated in the black liquor in samples pretreated using 1-butanol or 1-pentanol as the solvent; however, the major linkage structure was lost.

Which lignin constituent is most affected by 1-butanol or 1-pentanol was also investigated by comparing $2 \mathrm{D}$ NMR signals of solid fractions obtained by pretreatment with no solvent (control), 1-butanol, or 1-pentanol (Fig. 6 and Additional file 3). Compared with the solid fraction obtained using no solvent (control), signals related to $p$-coumarate (ROIs 2-6) were weaker in solid fractions obtained using 1-butanol or 1-pentanol as the solvent. In addition, the signals related to guaiacyl (ROI 10 ), syringyl (ROIs 11 and 12), and minor $\beta-\mathrm{O}-4$ interunits (ROIs 21-23, 26, and 27) in solid fractions obtained using 1-butanol or 1-pentanol as the solvent were weaker compared with the control. Accordingly, because the guaiacyl, syringyl, and $\beta-\mathrm{O}-4$ units contain a methoxyl side chain, methoxyl-related signals (ROIs 17 and 18) were weaker in solid fractions obtained using 1-butanol or 1-pentanol [23]. The removal of $p$-coumarate, syringyl, and guaiacyl from the solid fraction using 1-butanol or 1-pentanol corresponded with the results of increased aromatic lignin regions in the black liquor fraction and decreased acid-insoluble content in the solid fraction.

\section{Ethanol fermentation using the solid fraction}

The solid fraction obtained after organosolv pretreatment can be utilized as a sugar source for microbial fermentation. The solid fractions obtained after organosolv pretreatment using 1-butanol or 1-pentanol as the solvent were subjected to simultaneous saccharification and fermentation by $S$. cerevisiae. Ethanol production using each of these solid fractions was compared with that obtained with control solid fraction (Fig. 7). As expected, the ethanol production rates obtained with solid fractions of samples pretreated with 1-butanol or 1-pentanol (2.6 and $2.8 \mathrm{~g} / \mathrm{L} / \mathrm{h}$, respectively) were about 1.6 times higher in the first $9 \mathrm{~h}$ than those obtained with the solid fraction of samples pretreated with no solvent $(1.6 \mathrm{~g} / \mathrm{L} / \mathrm{h})$. After $96 \mathrm{~h}$ of fermentation, ethanol production from the 1-butanol and 1-pentanol solid fractions was about twice that of the control, reaching 43.1 and $47.2 \mathrm{~g} / \mathrm{L}$, respectively. In addition, the theoretical ethanol yield from the 1-butanol and 1-pentanol solid fractions was 59.6 and $62.1 \%$, respectively, compared with $32.4 \%$ for the control. As suggested previously [26], organosolv delignification and the resultant supply of readily hydrolyzable cellulose substrates results in an increase in the concentration of microbial fermentation products.

\section{Conclusions}

Sorghum bagasse was fractionated by organosolv pretreatment using various solvents at a low concentration of $12.5 \%$. The catalyst for the reaction was $1 \%$ sulfuric acid, and the reaction was carried out at $180{ }^{\circ} \mathrm{C}$ for $45 \mathrm{~min}$. Pretreatment with the highly hydrophobic solvents 1-butanol and 1-pentanol produced three visible fractions (i.e., a cellulose-enriched solid fraction, a liquid fraction containing hemicellulose-derived xylose, and a black liquor fraction containing lignin). However, only two fractions were produced upon pretreatment with ethanol, 1-propanol, or 2-propanol (i.e., a solid fraction containing cellulose and a liquid fraction containing xylose), and recovery of lignin was difficult. 2D NMR spectroscopy revealed that the black liquor fraction contained lignin aromatic components, such as guaiacyl, syringyl, $p$-hydroxyphenyl, $p$-coumarate, and ferulate. The aliphatic $\beta-\mathrm{O}-4$ unit of lignin was absent 


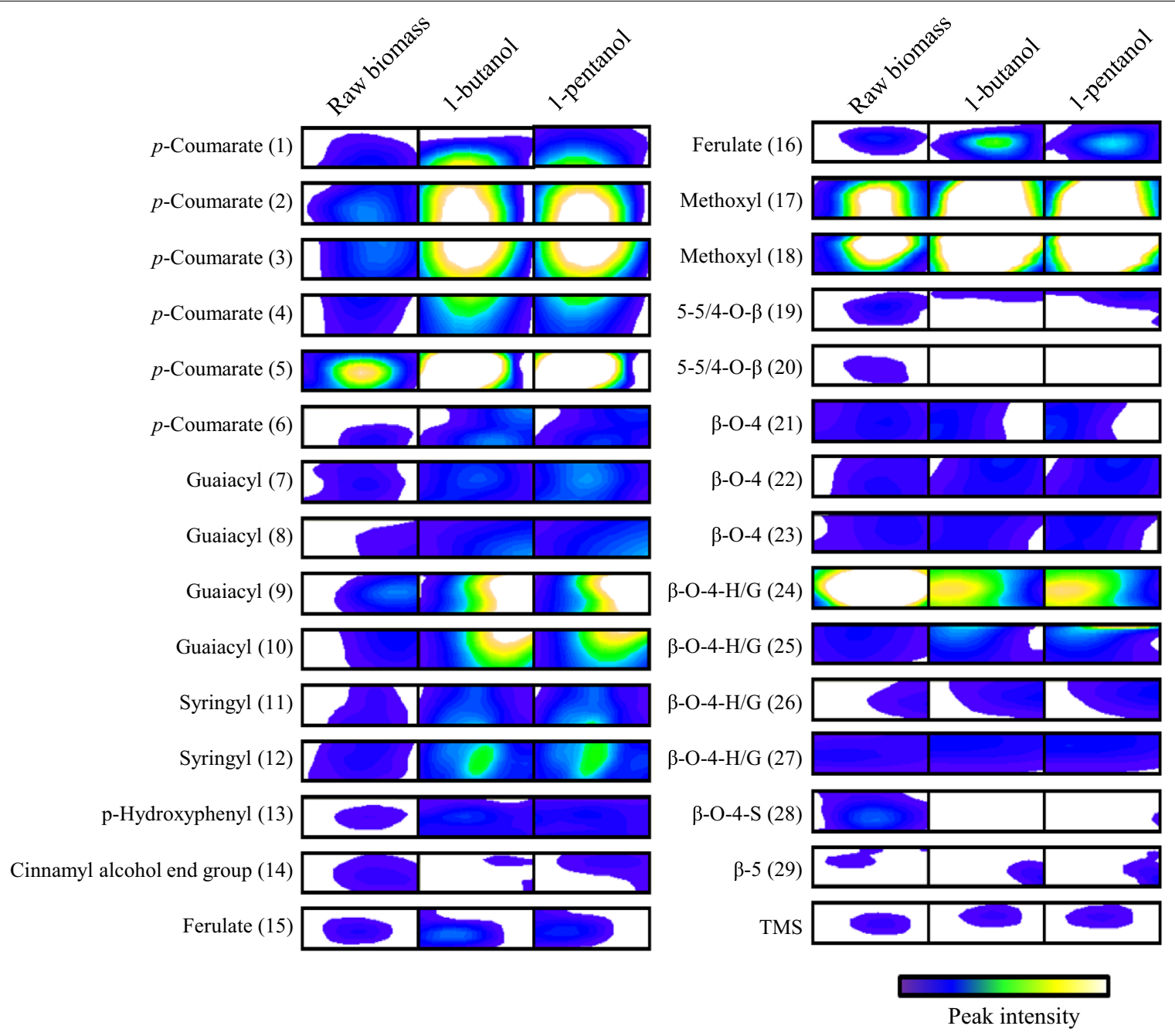

Fig. 5 Peaks of raw sorghum bagasse and black liquor. Left portion of figure shows NMR peaks of raw biomass. Middle and right portions of figure show NMR peaks of black liquor obtained after organosolv pretreatment of sorghum bagasse using 1-butanol or 1-pentanol as the solvent, respectively

in the black liquor fraction. Pretreatment with 1-butanol or 1-pentanol effectively removed $p$-coumarate, syringyl, and some of the guaiacyl from raw sorghum bagasse. The 1-butanol or 1-pentanol should be recovered after pretreatment and recycled using separation technologies such as pervaporation [27, 28]. We demonstrated here the effective organosolv pretreatment of sorghum bagasse using a low concentration of hydrophobic solvent (1-butanol or 1-pentanol).

\section{Methods}

Plant materials

The hybrid sorghum cultivar Tentaka [29] was grown in 2013 at an experimental field in Okinawa, Japan. Whole plants were harvested at the heading stage and then fully dried in a greenhouse. After removal of the panicles, the culms were ground into a fine powder using a blender (WB-1; TGK, Hachioji, Japan) fitted with a 2-mm screen.

\section{Organosolv pretreatment}

Organosolv pretreatment was performed using a laboratory-scale thermostirrer (HHE-19G-U; Koike Precision Instruments, Kanagawa, Japan) having a total volume of $100 \mathrm{~mL}$. Sorghum bagasse powder (6 g) was suspended in $80 \mathrm{~mL}$ of aqueous solution. The aqueous solution included $70 \mathrm{~mL}$ of $1 \%$ sulfuric acid and $10 \mathrm{~mL}$ of solvent (ethanol, 1-propanol, 2-propanol, 1-butanol, or 1 -pentanol). An aqueous solution consisting of $80 \mathrm{~mL}$ of $1 \%$ sulfuric acid was used as the control. Next, the mixture was treated at $180{ }^{\circ} \mathrm{C}$ for $45 \mathrm{~min}$, with agitation at 


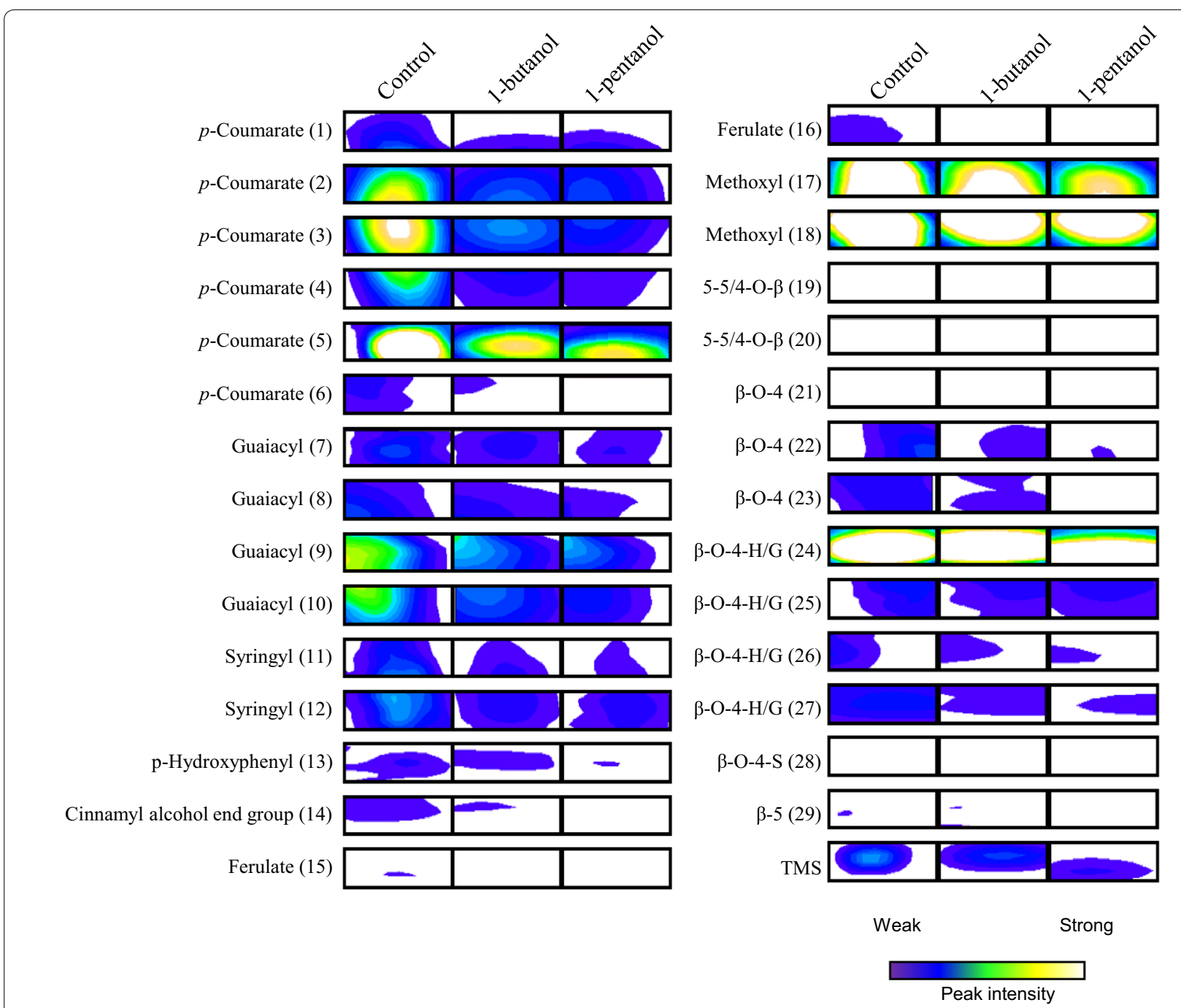

Fig. 6 Peak of solid fractions. Left, middle, and right portions of figure show NMR peaks of the solid fractions obtained by organosolv pretreatment of sorghum bagasse using no solvent (control) and 1-butanol and 1-pentanol as the solvent, respectively

$200 \mathrm{rpm}$. The optimal temperature and agitation speed for pretreatment were determined according to a previous report [30]. After pretreatment, the mixture was centrifuged at $3500 \mathrm{rpm}$ for $10 \mathrm{~min}$ for fractionation. Solid and liquid fractions were obtained under the control condition and with ethanol, 1-propanol, or 2-propanol (Fig. 1). When using 1-butanol or 1-pentanol as the solvent, the supernatant including the liquid and black liquor fractions was recovered and again centrifuged at $3500 \mathrm{rpm}$ for $10 \mathrm{~min}$ in order to separate the fractions. The upper phase contained the black liquor fraction, and the lower phase contained the liquid fraction. The solid fraction was washed with deionized water, neutralized to $\mathrm{pH}$ 7.0, then dried; the dry weight was measured using an electronic balance (XS105DU; Mettler Toledo,
Greifensee, Switzerland). Lignin was separated from the black liquor fraction by precipitation upon dilution with $80 \mathrm{~mL}$ of water. The compositions of cellulose, hemicellulose, acid-insoluble lignin, acid-soluble lignin, and ash were determined according to the National Renewable Energy Laboratory method [31].

\section{Sugar analysis}

Sugar analysis was performed as described previously [30]. The liquid fraction was neutralized to $\mathrm{pH} 5.0$ by the addition of calcium hydroxide. An aliquot of sample $(1.5 \mu \mathrm{L})$ was mixed with $1.5 \mu \mathrm{L}$ of $0.1 \%(w / w)$ Ribitol as internal standard, and then the mixture was dried in a vacuum concentrator (7810010; Labconco, Kansas City, MO, USA). The dried residue was dissolved in $100 \mu \mathrm{L}$ of $20 \mathrm{mg} / \mathrm{mL}$ of 


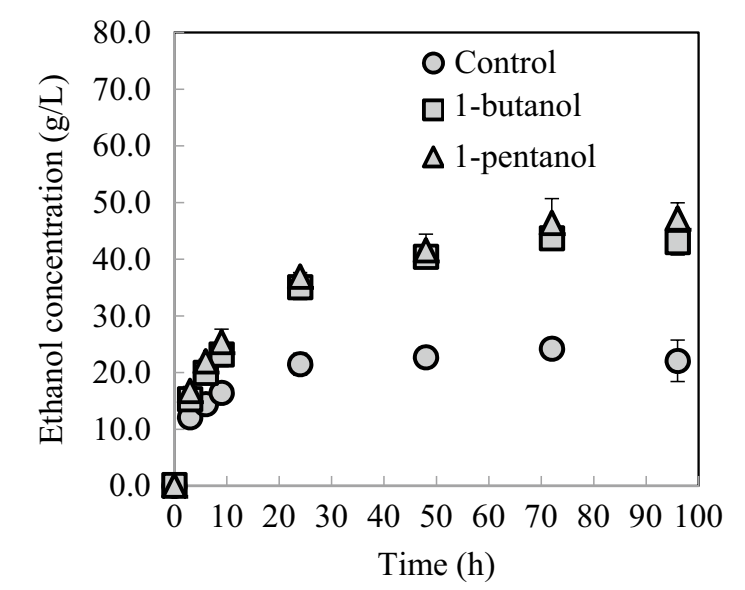

Fig. 7 Simultaneous saccharification and fermentation of solid fractions by Saccharomyces cerevisiae. Solid fractions were obtained by organosolv pretreatment of sorghum bagasse using 1-butanol (closed square) and 1-pentanol (closed triangle) as the solvent and no solvent (closed circle). Ethanol fermentation was initiated from $200 \mathrm{~g} / \mathrm{L}$ of solid fraction

methoxyamine hydrochloride in pyridine and incubated at $30{ }^{\circ} \mathrm{C}$ for $90 \mathrm{~min}$, after which $50 \mu \mathrm{L}$ of $\mathrm{N}$-methyl- $\mathrm{N}$-trimethylsilyltrifluoroacetamide was added and the sample was incubated at $37^{\circ} \mathrm{C}$ for $30 \mathrm{~min}$. A $10 \mu \mathrm{L}$ aliquot of the solution was subjected to gas chromatography-mass spectrometry (GC-MS) (GCMS-2010plus; Shimadzu, Kyoto, Japan) under the following conditions: column, Agilent CP-Sil 8CB-MS (30 m $\times 0.25 \mathrm{~mm})$; carrier gas, helium; injection temperature, $230{ }^{\circ} \mathrm{C}$; oven temperature, $80^{\circ} \mathrm{C}$ at $t=0-2 \mathrm{~min}$, then increased to $330^{\circ} \mathrm{C}$ at $15^{\circ} \mathrm{C} / \mathrm{min}$.

\section{Byproduct analysis}

Byproduct analysis was performed as described previously [30]. Acetone $(900 \mu \mathrm{L})$ was added to $100 \mu \mathrm{L}$ of liquid fraction and mixed thoroughly. The sample was then centrifuged at $21,880 \times g$ and room temperature for $10 \mathrm{~min}$. The supernatant $(10 \mu \mathrm{L})$ was subjected to GCMS analysis (GC-MS-2010plus; Shimadzu). 5-HMF and furfural were analyzed under the following conditions: column, Agilent CP-Sil 8CB-MS (30 m $\times 0.25 \mathrm{~mm})$; carrier gas, helium; injection temperature, $250^{\circ} \mathrm{C}$; oven temperature, $50{ }^{\circ} \mathrm{C}$ at $t=0-5 \mathrm{~min}$, then increased to $280^{\circ} \mathrm{C}$ at $20^{\circ} \mathrm{C} / \mathrm{min}$. Acetic acid and formic acid were analyzed under the following conditions: column, Agilent DBFFAP $(60 \mathrm{~m} \times 0.25 \mathrm{~mm})$; carrier gas, helium; injection temperature, $250{ }^{\circ} \mathrm{C}$; oven temperature, $100{ }^{\circ} \mathrm{C}$ at $t=0$ to $5 \mathrm{~min}$, then increased to $230^{\circ} \mathrm{C}$ at $10^{\circ} \mathrm{C} / \mathrm{min}$.

\section{Enzymatic saccharification}

Enzymatic saccharification of the solid fraction (10 \% dry weight) was performed by adding $0.3 \mathrm{M}$ citrate buffer
( $\mathrm{pH}$ 4.8) and cellulase (Celic CTec2, Novozyme, Bagsvaerd, Denmark) at a concentration of 6.6 filter paper units (FPU)/g-dry biomass. Tetracycline $(40 \mu \mathrm{g} / \mathrm{mL})$ and cycloheximide $(30 \mu \mathrm{g} / \mathrm{mL})$ were added to prevent microbial growth. The reaction mixture was incubated at $50{ }^{\circ} \mathrm{C}$ in a chemi station (PPS-2000, Tokyo Rikakikai, Tokyo, Japan) with agitation at $120 \mathrm{rpm}$ for $72 \mathrm{~h}$. Enzymatic saccharification was stopped by rapid chilling on ice, followed by centrifugation at $21,880 \times g$ for $10 \mathrm{~min}$ at $4{ }^{\circ} \mathrm{C}$. The sugars in the supernatant were analyzed as described above.

\section{Composition analysis}

Compositional analysis was performed according to the National Renewable Energy Laboratory (NREL) method [31]. Obtained sugar was analyzed as described above. The amount of acid-soluble lignin was determined by measuring the optical density (OD) at $240 \mathrm{~nm}$.

\section{Solution 2D NMR spectroscopy}

Sample preparation for solubilized lignocelluloses was similar to previously reported methods [32,33]. Briefly, the dried sample was further ground using a Pulverisette 5 ball mill (Fritsch GmbH, Idar-Oberstein, Germany). The ball-milled powder $(30 \mathrm{mg})$ was mixed with $600 \mu \mathrm{L}$ of dimethyl sulfoxide (DMSO)- $\mathrm{d}_{6}$ : Pyridine- $_{5}$ (4:1), heated at $50{ }^{\circ} \mathrm{C}$ for $30 \mathrm{~min}$ in a Thermomixer Comfort (Eppendorf AG, Hamburg, Germany), then centrifuged at $20,380 \times g$ for $5 \mathrm{~min}$. The supernatant was transferred to 5-mm $\phi$ NMR tubes and subjected to NMR analysis. NMR spectra were recorded on an Avance III HD-600 (Bruker, Billerica, MA, USA) equipped with a 5-mm TXIcryoprobe operated at $600 \mathrm{MHz}$ for ${ }^{1} \mathrm{H}$ - and $125 \mathrm{MHz}$ for ${ }^{13} \mathrm{C}$-NMR. The temperature of all NMR samples was maintained at $319 \mathrm{~K}$. The chemical shifts were referenced to the methyl group of DMSO- $\mathrm{d}_{6}$ at ${ }^{13} \mathrm{C}=40.03 \mathrm{ppm}$ and ${ }^{1} \mathrm{H}=2.582 \mathrm{ppm}$.

Two-dimensional ${ }^{1} \mathrm{H}_{-}{ }^{13} \mathrm{C}$ heteronuclear single-quantum spectra were collected using echo/antiecho gradient selection (the hsqcetgp pulse program in the Bruker library). Forty-eight regions of interest (ROIs) were compared with previously assigned chemical shifts [23, 34]. ROI details are described in Additional file 4.

\section{Liquefaction and ethanol fermentation}

Liquefaction of the solid fraction was performed in a $50 \mathrm{~mL}$ polypropylene tube (Corning Inc., NY, USA) set in a Thermo Block Rotator SN-06BN heat block (Nissin, Tokyo, Japan), as described previously [35]. The tube was closed with a silicone plug (As One, Osaka, Japan), into which a hole was made using a disposable needle ( $\phi=0.6 \mathrm{~mm})$ (Termo Corp., Tokyo, Japan). In the tube, the solid fraction (final weight $200 \mathrm{~g} / \mathrm{L}$ ) was mixed with 
medium containing $50 \mathrm{mM}$ citric acid buffer ( $\mathrm{pH} 5.0$ ) and 6.6 FPU/g-biomass of commercial cellulase (Cellic CTec2; Novozymes Inc., Bagsvaerd, Denmark) and axially rotated at $35 \mathrm{rpm}$ at $50^{\circ} \mathrm{C}$ for $2 \mathrm{~h}$.

Saccharomyces cerevisiae strain BY4741 (genotype: MATa his $3 \Delta 1$ leu $2 \Delta 0$ met $15 \Delta 0$ ura3 $\Delta 0$ ) [36] was purchased from the American Type Culture Collection (ATCC) as ATCC No. 404002. The cells were aerobically propagated for $24 \mathrm{~h}$ at $30{ }^{\circ} \mathrm{C}$ and $150 \mathrm{rpm}$ in $5 \mathrm{~mL}$ of YPD medium $[10 \mathrm{~g} / \mathrm{L}$ yeast extract [Becton, Dickinson and Company, Tokyo, Japan], 20/g L polypeptone (Wako Pure Chemical Industries, Ltd., Osaka, Japan), and 20 g/L glucose], and then cultivated for $24 \mathrm{~h}$ in $500 \mathrm{~mL}$ of YPD medium. The cells were collected by centrifugation at $3000 \times g$ for $10 \mathrm{~min}$ at $4{ }^{\circ} \mathrm{C}$ and washed twice with distilled water. Ethanol fermentation was initiated by the addition of yeast extract (final concentration $10 \mathrm{~g} / \mathrm{L}$ ), peptone (final concentration $20 \mathrm{~g} / \mathrm{L}$ ), and $S$. cerevisiae cells (50 g-wet cells/L, corresponding to $10 \mathrm{~g}$-dry cells/L) after $2 \mathrm{~h}$ of liquefaction of the solid fraction. Ethanol fermentation was conducted by axial agitation at $35 \mathrm{rpm}$ and $35^{\circ} \mathrm{C}$ for $48 \mathrm{~h}$. Theoretical ethanol yield (\%) was calculated as the percent of $0.511 \mathrm{~g}$-ethanol/g-sugar of consumed glucose as follows:

$$
\text { Ethanol yield }=\frac{\text { Ethanol produced }(\mathrm{g})}{\text { Glucan in solid fraction }(\mathrm{g})}
$$

\section{Additional files}

\begin{abstract}
Additional file 1. Mass balance of glucose, xylose and lignin. Black bar, lined bar, gray bar, open bar and dotted bar indicated recovery in solid fraction, liquid fraction, liquid fraction byproduct, black liquor and unknown. (A) Mass balance of glucose. Liquid fraction byproduct and black liquor mean 5-HMF. (B) Mass balance of xylose. Liquid fraction byproduct and black liquor mean furfural. (C) Mass balance of lignin.
\end{abstract}

Additional file 2. Peak intensities obtained by 2D NMR analysis of raw sorghum bagasse and black liquor. Black liquor was obtained after organosolv pretreatment of sorghum bagasse using 1-butanol or 1-pentanol as the solvent. Blue bar indicates peak intensity of raw sorghum bagasse. Orange and green bars indicate peak intensities of the solid fraction obtained using 1-butanol and 1-pentanol as the solvent, respectively.

Additional file 3. Peak intensities obtained by 2D NMR analysis of solid fractions. The solid fractions were obtained by organosolv pretreatment of sorghum bagasse using 1-butanol and 1-pentanol as the solvent and no solvent (control). Red, orange, and blue bars indicate solid fraction pretreated with no solvent, 1-butanol, and 1-pentanol, respectively.

Additional file 4. Annotation of each $2 \mathrm{D}^{1} \mathrm{H}^{-13} \mathrm{C}$ HSQC NMR spectrum peak.

\section{Abbreviations}

$2 D^{1} \mathrm{H}^{-13} \mathrm{C}$ HSQC NMR: two-dimensional ${ }^{1} \mathrm{H}-{ }^{-13} \mathrm{C}$ heteronuclear single-quantum coherence nuclear magnetic resonance; ROI: region of interest; 5-HMF: 5-hydroxymethylfurfural; GC-MS: gas chromatography-mass spectrometry; FPU: filter paper units.

\section{Authors' contributions}

$H T, K S$, and AK designed this study and drafted the manuscript. HT, TO, and HK-a performed the biomass pretreatment and compositional analysis. MO, TS-h, FM, and JK carried out the NMR analysis and interpreted the NMR results. HK-a and $\mathrm{CO}$ analyzed sugars and byproducts. KH, TS-a, and HK-i prepared the sorghum bagasse and helped to revise the manuscript. TO and FM performed enzymatic saccharification. KS and AK performed ethanol fermentation. MO, TS-h, and JK revised the manuscript. All authors read and approved the final manuscript.

\section{Author details}

${ }^{1}$ Department of Chemical Science and Engineering, Graduate School of Engineering, Kobe University, 1-1 Rokkodaicho, Nada-ku, Hyogo, Kobe 657-8501, Japan. ${ }^{2}$ Organization of Advanced Science and Technology, Kobe University, 1-1 Rokkodaicho, Nada-ku, Hyogo, Kobe 657-8501, Japan. ${ }^{3}$ Department of Bioinformatic Engineering, Graduate School of Information Science and Technology, Osaka University, 1-5 Yamadaoka, Osaka, Suita 565-0871, Japan. ${ }^{4}$ RIKEN Center for Sustainable Resource Science, 1-7-22 Suehiro-cho, Tsurumi-ku, Kanagawa, Yokohama 230-0045, Japan. ${ }^{5}$ Bioscience and Biotechnology Center, Nagoya University, 1 Furo-cho, Chikusa-ku, Nagoya 464-8601, Japan. ${ }^{6}$ Graduate School of Medical Life Science, Yokohama City University, 1-7-29 Suehirocho, Tsurumi-ku, Yokohama 230-0045, Japan. ${ }^{7}$ Graduate School of Bioagricultural Sciences and School of Agricultural Sciences, Nagoya University, 1 Furo-cho, Chikusa-ku, Nagoya 464-8601, Japan.

\section{Acknowledgements}

This work was supported in part by Grants-in-Aid from the NC-CARP project of the Ministry of Education, Culture, Sports, Science and Technology, Japan, and by the Special Coordination Fund for the Promotion of Science and Technology, Creation of Innovation Centers for Advanced Interdisciplinary Research Areas (Innovative Bioproduction Kobe), MEXT, Japan.

\section{Competing interests}

The authors declare that they have no competing interests.

Received: 9 October 2015 Accepted: 5 January 2016

Published online: 02 February 2016

\section{References}

1. Tanaka T, Kondo A. Cell surface engineering of industrial microorganisms for biorefining applications. Biotechnol Adv. 2015;33:1403-11.

2. Zhao X, Cheng K, Liu D. Organosolv pretreatment of lignocellulosic biomass for enzymatic hydrolysis. Appl Microbiol Biotechnol. 2009;82:815-27.

3. Rooney WL, Blumenthal J, Bean B, Mullet JE. Designing sorghum as a dedicated bioenergy feedstock. Biofuels Bioprod Bioref. 2007;1:147-57.

4. Kim M, Day DF. Composition of sugar cane, energy cane, and sweet sorghum suitable for ethanol production at Louisiana sugar mills. J Ind Microbiol Biotechnol. 2011;38:803-7.

5. Wildschut J, Smit AT, Reith JH, Huijgen WJ. Ethanol-based organosolv fractionation of wheat straw for the production of lignin and enzymatically digestible cellulose. Bioresour Technol. 2013;135:58-66.

6. Zakzeski J, Bruijnincx PCA, Jongerius AL, Weckhuysen BM. The catalytic valorization of lignin for the production of renewable chemicals. Chem Rev. 2010;110:3552-99.

7. Huber GW, Iborra S, Corma A. Synthesis of transportation fuels from biomass: chemistry, catalysts, and engineering. Chem Rev. 2006;106:4044-98.

8. Lan W, Liu CF, Sun RC. Fractionation of bagasse into cellulose, hemicellulose, and lignin with ionic liquid treatment followed by alkaline extraction. J Agric Food Chem. 2011;59:8691-701.

9. Mosier N, Wyman C, Dale B, Elander R, Lee YY, Holtzapple M, Ladisch M. Feature of promising technologies for pretreatment of lignocellulosic biomass. Bioresour Technol. 2005;96:673-86.

10. Sun Y, Cheng J. Hydrolysis of lignocellulosic materials for ethanol production: a review. Bioresour Technol. 2002;83:1-11.

11. Huijgen WJJ, Smit AT, de Wild PJ, den Uil H. Fractionation of wheat straw by prehydrolysis, organosolv delignification and enzymatic hydrolysis for production of sugars and lignin. Bioresour Technol. 2012;114:389-98. 
12. Zhang K, Pei Z, Wang D. Organic solvent pretreatment of lignocellulosic biomass for biofuels and biochemicals: a review. Bioresour Technol. 2016;199:21-33

13. Taherzaden M, Karimi K. Pretreatment of lignocellulosic wastes to improve ethanol and biogas production: a review. Int J Mol Sci. 2008;9:1621-51.

14. Tsuji $Y$, Vanholme R, Tobimatsu Y, Ishikawa Y, Foster CE, Kamimura N, et al Introduction of chemically labile substructures into Arabidopsis lignin through the use of LigD, the Ca-dehydrogenase from Sphingobium sp. strain SYK-6. Plant Biotechnol J. 2015;13:821-32.

15. Mansfield SD, Kim H, Lu F, Ralph J. Whole plant cell wall characterization using solution-state 2D NMR. Nat Protoc. 2012;7:1579-89.

16. Teramura H, Sasaki K, Oshima T, Aikawa S, Matsuda F, Okamoto M, et al. Changes in lignin and polysaccharide components in 13 cultivars of rice straw following dilute acid pretreatment as studied by solution-state 2D ${ }^{1} \mathrm{H}-^{13} \mathrm{C}$ NMR. PLoS One. 2015;10:e0128417.

17. Selig MJ, Viamajala S, Decker SR, Tucker MP, Himmel ME, Vinzant TB. Deposition of lignin droplets produced during dilute acid pretreatment of maize stems retards enzymatic hydrolysis of cellulose. Biotechnol Prog. 2007:23:1333-9.

18. Alvira P, Tomás-Pejó E, Ballesteros M, Negro MJ. Pretreatment technologies for an efficient bioethanol production process based on enzymatic hydrolysis: a review. Bioresour Technol. 2010;101:4851-61.

19. Weng YH, Wei HJ, Tsai TY, Lin TH, Wei TY, Guo GL, et al. Separation of furans and carboxylic acids from sugars in dilute acid rice straw hydrolysates by nanofiltration. Bioresour Technol. 2010;101:4889-94.

20. He Y, Bagley DM, Leung KT, Liss SN, Liao BQ. Recent advances in membrane technologies for biorefining and bioenergy production. Biotechnol Adv. 2012;30:817-58.

21. Perez-Cantu L, Schreiber A, Schütt F, Saake B, Kirsch C, Smirnova I. Comparison of pretreatment methods for rye straw in the second generation biorefinery: effect on cellulase, hemicellulase and lignin recovery. Bioresour Technol. 2013;142:428-35.

22. Chylla RA, Van Acker R, Kim H, Azapira A, Mukerjee P, Markley JL, et al. Plant cell wall profiling by fast maximum likelihood reconstruction (FMLR) and region-of-interest (ROI) segmentation of solution-state $2 \mathrm{D}{ }^{1} \mathrm{H}-{ }^{13} \mathrm{C}$ NMR spectra. Biotechnol Biofuels. 2013;6:45.

23. Kim H, Ralph J. Solution-state $2 D$ NMR of ball-milled plant cell wall gels in DMSO-d6/pyridine-d5. Org Biomol Chem. 2010;8:576-91.

24. Kim JY, Hwang H, Oh S, Kim YS, Kim UJ, Choi JW. Investigation of structural modification and thermal characteristics of lignin after heat treatment. Int J Biol Macromol. 2014;66:57-65.
25. Trajano HL, Engle NL, Foston M, Ragauskas AJ, Tschaplinski TJ, Wyman CE. The fate of lignin during hydrothermal pretreatment. Biotechnol Biofuels. 2013;6:110.

26. Pan X, Gilkes N, Kadla J, Pye K, Saka S, Gregg D, et al. Bioconversion of hybrid poplar to ethanol and co-products using an organosolv fractionation process: optimization of process yield. Biotechnol Bioeng. 2006;94:851-61.

27. Xue C, Du GQ, Chen LJ, Ren JG, Sun JX, Bai FW, et al. A carbon nanotube filled polydimethylsiloxane hybrid membrane for enhanced butanol recovery. Sci Rep. 2014;4:5925.

28. Negishi H, Sakaki K, Ikegami T. Silicalite pervaporation membrane exhibiting a separation factor of over 400 for butanol. Chem Lett. 2010;39:1312-4

29. Venuto B, Kindiger B. Forage and biomass feedstock production from hybrid forage sorghum and sorghum-sudangrass hybrids. Jpn Soc Grassl Sci. 2008;54:189-96

30. Matsuda F, Yamasaki M, Hasunuma T, Ogino C, Kondo A. Variation in biomass properties among rice diverse cultivars. Biosci Biotechnol Biochem. 2011;75:1603-5.

31. Sluiter A, Hames B, Ruiz R, Scarlata C, Sluiter J, Templeton D, et al. Determination of structural carbohydrates and lignin in biomass. Golden: Natl Renew Energy Lab; 2011.

32. Meng X, Foston M, Leisen J, DeMartini J, Wyman CE, Ragauskas AJ. Determination of porosity of lignocellulosic biomass before and after pretreatment by using Simons' stain and NMR techniques. Bioresour Technol. 2013;144:467-76.

33. Komatsu T, Kikuchi J. Comprehensive signal assignment of 13C-labeled lignocellulose using multidimensional solution NMR and 13C chemical shift comparison with solid-state NMR. Anal Chem. 2013;85:8857-65.

34. Okushita K, Komatsu T, Chikayama E, Kikuchi J. Statistical approach for solid-state NMR spectra of cellulose derived from a series of variable parameters. Polym J. 2012;44:895-900.

35. Matano Y, Hasunuma T, Kondo A. Display of cellulases on the cell surface of Saccharomyces cerevisiae for high yield ethanol production from highsolid lignocellulosic biomass. Bioresour Technol. 2012;108:128-33.

36. Brachmann CB, Davies A, Cost GJ, Caputo E, Li J, Hieter P, et al. Designer deletion strains derived from Saccharomyces cerevisiae S288C: a useful set of strains and plasmids for PCR-mediated gene disruption and other applications. Yeast. 1998;14:115-32.

\section{Submit your next manuscript to BioMed Central and we will help you at every step:}

- We accept pre-submission inquiries

- Our selector tool helps you to find the most relevant journal

- We provide round the clock customer support

- Convenient online submission

- Thorough peer review

- Inclusion in PubMed and all major indexing services

- Maximum visibility for your research

Submit your manuscript at www.biomedcentral.com/submit

\section{() Biomed Central}

